\section{UJMM

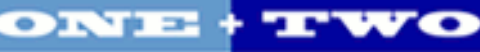

Volume 6 | 2014 Fall

\section{Undergraduate Journal of Mathematical}

Modeling: One + Two

2014

\title{
Rocket Flight Path
}

Jamie Waters

University of South Florida

\author{
Advisors: \\ Ihor Luhach, Mathematics and Statistics \\ Scott Campbell, Chemical and Biomedical Engineering \\ Problem Suggested By: Scott Campbell
}

Follow this and additional works at: https://digitalcommons.usf.edu/ujmm

Part of the Aeronautical Vehicles Commons, Mathematics Commons, and the Physics Commons

UJMM is an open access journal, free to authors and readers, and relies on your support:

Donate Now

\section{Recommended Citation}

Waters, Jamie (2014) "Rocket Flight Path," Undergraduate Journal of Mathematical Modeling: One + Two: Vol. 6: Iss. 1, Article 2.

DOI: http://dx.doi.org/10.5038/2326-3652.6.1.4858

Available at: https://digitalcommons.usf.edu/ujmm/vol6/iss1/2 


\title{
Rocket Flight Path
}

\begin{abstract}
This project uses Newton's Second Law of Motion, Euler's method, basic physics, and basic calculus to model the flight path of a rocket. From this, one can find the height and velocity at any point from launch to the maximum altitude, or apogee. This can then be compared to the actual values to see if the method of estimation is a plausible. The rocket used for this project is modeled after Bullistic- 1 which was launched by the Society of Aeronautics and Rocketry at the University of South Florida.
\end{abstract}

\section{Keywords}

rocket, Euler's method, flight path, ballistic 


\section{PROBLEM STATEMENT}

The purpose of this project was to derive a model to simulate the forces on a rocket through its flight path. The correct flight path of a rocket is shown in Figure 1. The model is derived from a free-body diagram on the rocket showing all of the forces on the rocket. Euler's method is then used to account for the forces over the entire flight path and used to give a numerical solution at any instant for the duration of the flight. This model is then used to estimate the rocket's maximum altitude and velocity prior to the launch, and compare it to the actual flight path to see how accurate the method is.

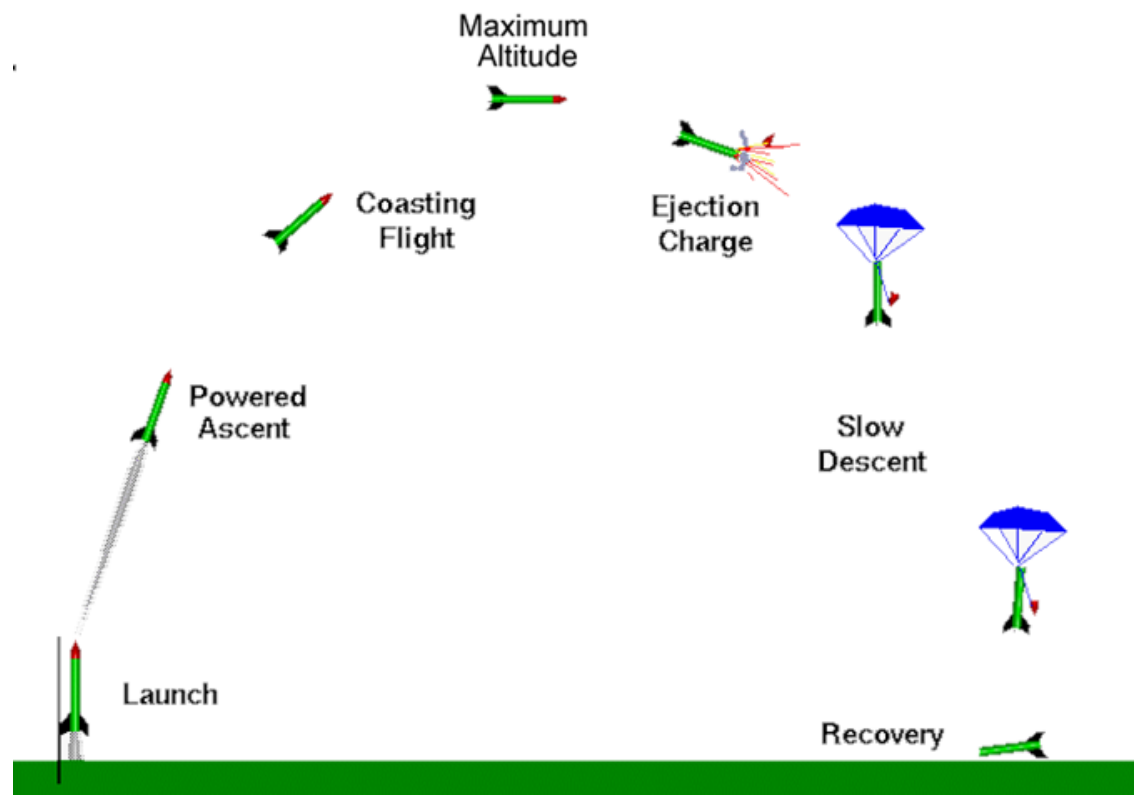

Figure 1: Correct rocket flight path (Flight of a Model Rocket). 


\section{MOTIVATION}

In the field of rocketry, knowing the altitude and velocity at any point during flight is of the utmost importance. In the building stages of a rocket, this knowledge is important because the rocket may be modified to either go higher to reach a certain altitude, or go lower to refrain from breaking laws set by the Federal Aviation Administration (FAA). This can also be used to determine when a rocket can go super-sonic. When a rocket reaches super-sonic speeds, above 343 meters per second, the rocket comes in contact with extreme pressure and shock waves. These effects need to be accounted for to ensure the rocket's flight path is safe and stays on track. The Society of Aeronautics and Rocketry worked diligently to ensure that Bullistic-1 would have a safe flight (Figure 2). For this project, the objective was to get a rough estimate of these values to get a general idea of the flight path.

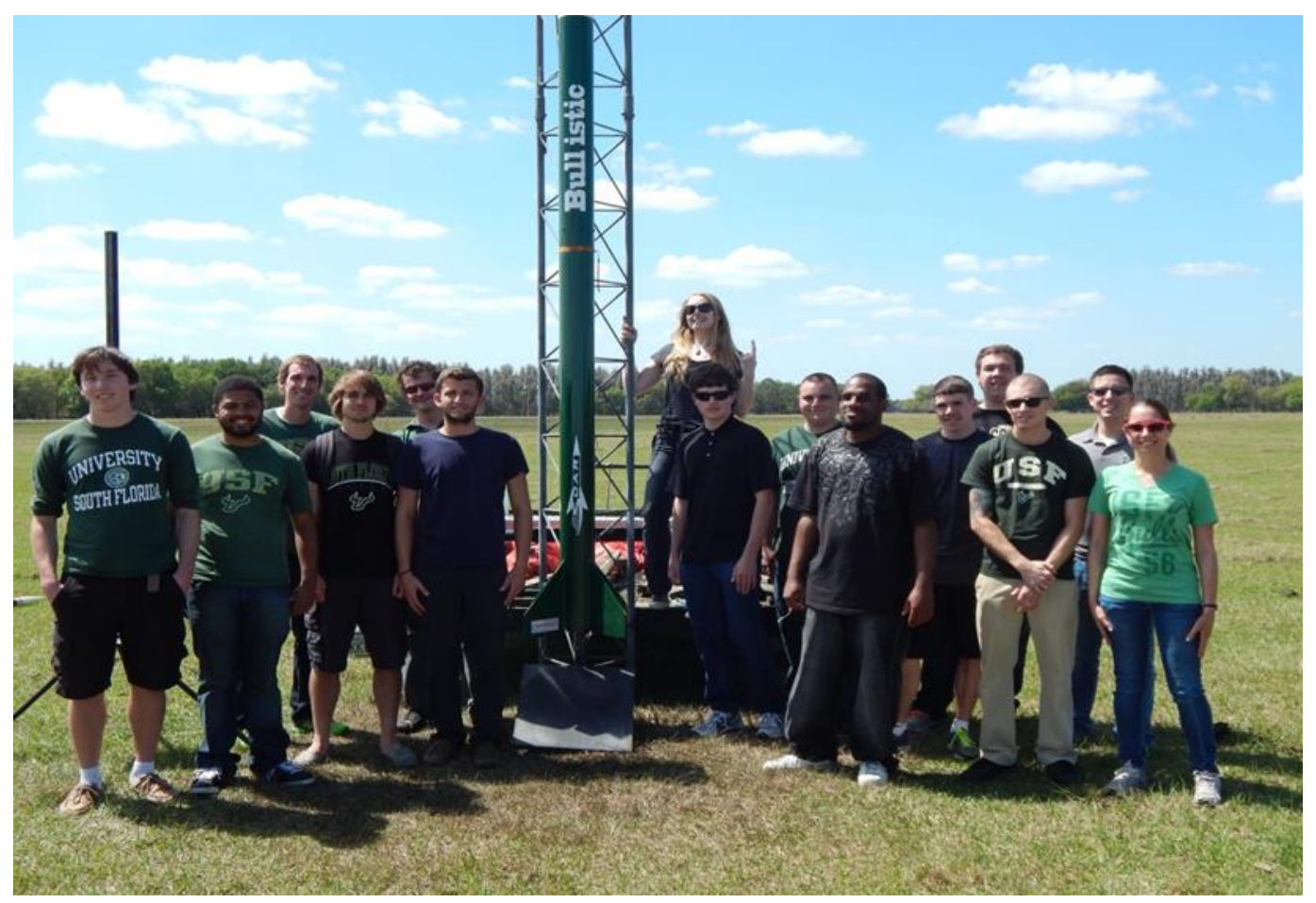

Figure 2: The Society of Aeronautics and Rocketry with Bullistic-1. 


\section{MATHEMATICAL DESCRIPTION AND SOLUTION APPROACH}

In order to begin finding the maximum height, a free-body diagram is used to find all of the forces a rocket body experiences in its flight. This diagram (Figure 3) shows the thrust, T, force of gravity, $\mathrm{F}_{\mathrm{G}}$, and force of drag, $\mathrm{F}_{\mathrm{D}}$, on the rocket.

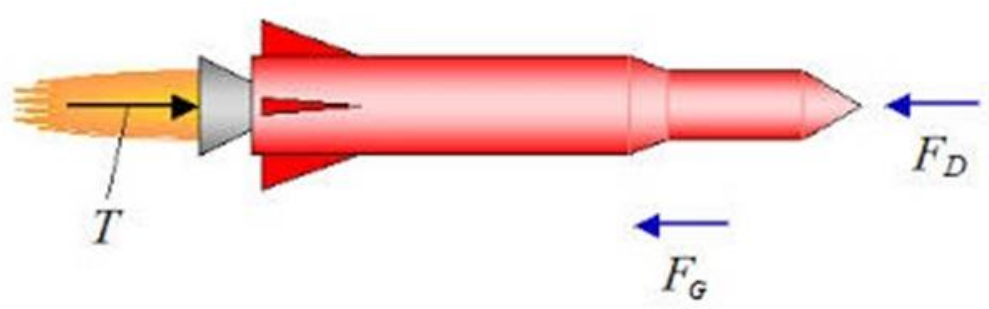

Figure 3: Free-body Diagram of Rocket (Rocket Physics).

The forces the rocket experiences can be written as the sum of the forces in the $y$-direction:

$$
\sum F_{y}=T-F_{G}-F_{D}
$$

Newton's second law of motion can be used in this scenario:

$$
\Sigma F_{y}=m * a_{y}(2)
$$

where $a_{y}$ is the acceleration in the y-direction and $\mathrm{m}$ is the mass of the rocket. By setting (1) and (2) equal to each other the equation becomes:

$$
m * a_{y}=T-F_{G}-F_{D}
$$

The force of drag on a rocket going up can be expressed as:

$$
F_{D}=k * v^{2}
$$


where $k$ is a coefficient that depends on the rocket and $v$ as the velocity. The force of gravity on a rocket can be expressed as:

$$
F_{G}=m * g
$$

where $g$ is the gravitational constant. The force of drag in (3) can be replaced by (4). The acceleration in the y-direction in (3) can be expressed as a derivative of velocity:

$$
a_{y}=\frac{d v}{d t}
$$

When solving for $\mathrm{dv} / \mathrm{dt}$, one gets equation 7 :

$$
\frac{d v}{d t}=\left(\frac{T}{m}-g-\frac{k}{m}\right) v^{2}
$$

For a rocket, $k$ can be expressed as:

$$
k=\frac{1}{2} * \rho_{\text {air }} * C_{D} * A
$$

where $\rho_{\text {air }}$ is the density of air, $C_{D}$ is the coefficient of drag, and $A$ is the area of the bottom of the rocket. The density of the air can be found by equation 9, which is a simplified form of the Ideal Gas Law:

$$
\rho_{\text {air }}=\frac{384.4484}{T_{\mathrm{k}}}
$$

where $T_{k}$ is the temperature in Kelvin. Since the temperature on the day of the launch was $307.35 \mathrm{~K}$, the density of air would be equal to $1.1337 \mathrm{~kg} / \mathrm{m}^{3}$. The area of the rocket from the bottom was $0.0270479 \mathrm{~m}^{2}$. The value for gravity used is $9.81 \mathrm{~m} / \mathrm{s}^{2}$ (Young). According to the 
National Aeronautics and Space Administration (NASA), the coefficient of drag can be estimated at .75 for a rocket (Shape Effects on Drag). With these values, the value for $k$ would be .011499 . The mass of the rocket is estimated using the final mass, $m_{f}$, and the initial mass, $m_{i}$, shown below.

$$
m=\frac{1}{2} *\left(m_{f}+m_{i}\right)
$$

The initial mass was measured to be $26.5 \mathrm{~kg}$ and the final mass was measured to be 23.55 $\mathrm{kg}$. This would make the mass used in further calculations to be $25.025 \mathrm{~kg}$. The other variables in (7), $T$ and $v$, are functions of time and vary over the course of flight. The velocity for a rocket can be defined as the derivative of position in the y-direction:

$$
\frac{d y}{d t}=v
$$

In order to get the velocity and altitude as a function of time, Euler's method is used to get a numerical solution. An analytical solution is not used for this because the function would have to be expressed through differential equations.. In this case, the thrust cannot be expressed easily, so the numerical solution must be used. Euler's method begins with the definition of the first derivative:

$$
f^{\prime}(t)=\lim _{\Delta t \rightarrow 0} \frac{f(t+\Delta t)-f(t)}{\Delta t}
$$

where $\Delta t$ is the change in time, $f(t)$ is the function of time, and $f^{\prime}(t)$ is the derivative of the function. This can be approximated by (13) where the smaller the $\Delta t$ is, the more accurate the approximation is. The $\Delta t$ used in the calculations is .1 seconds. 


$$
f^{\prime}(t) \approx \frac{f(t+\Delta t)-f(t)}{\Delta t}
$$

To use (13) to estimate the functions for velocity and altitude, we solve for $f(t+\Delta t)$, which is the current value of the function at a corresponding time (14).

$$
f(t+\Delta t)=f(t)+\left(\Delta t * f^{\prime}(t)\right)
$$

Equation 14 can be rewritten in terms of velocity (15) and position (16) to obtain the functions for both velocity and altitude.

$$
\begin{aligned}
& y(t)=y_{\text {prev }}+\left(\Delta t * y_{\text {prev }}^{\prime}\right) \\
& v(t)=v_{\text {prev }}+\left(\Delta t * v_{\text {prev }}^{\prime}\right)
\end{aligned}
$$

We can now begin calculating the flight path of the rocket. In excel, the time, thrust, derivative of velocity, velocity, derivative of position, and position are all put in row 1 . Under the "time" heading, value are inserted from 0 to 50 seconds in .1 second intervals to insure enough data points for accuracy. The entries in the "thrust" column come from a thrust curve off of a motor. Since this is going to be compared to an actual launch, the thrust curve that will be used it the one for the M1665WC (Figure 4), the motor used for in launch. The thrust at every tenth of a second is estimated. 


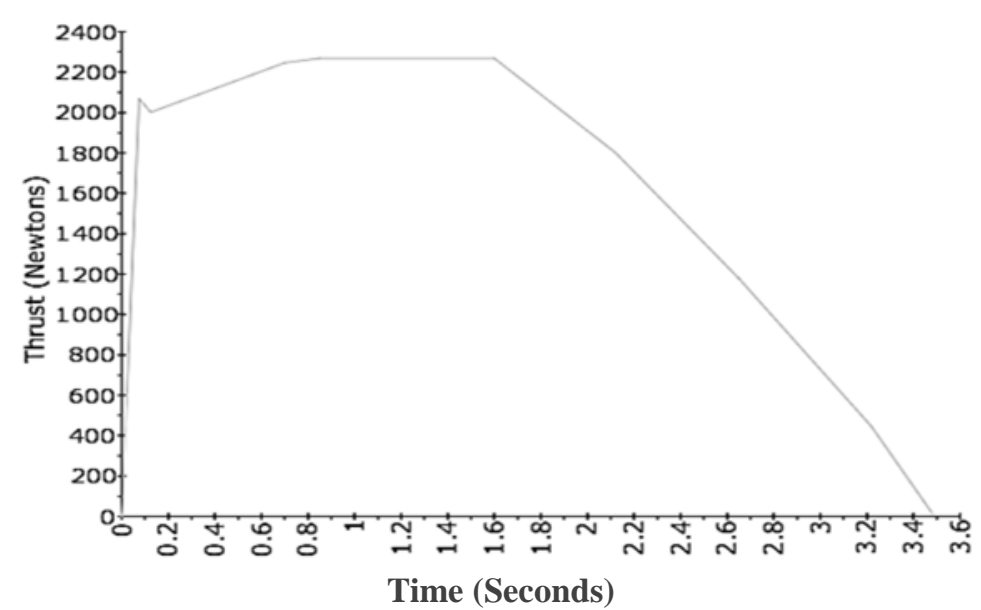

Figure 4: M1665WC thrust curve

In the "derivative of velocity" column, equation 7 is entered as a formula with the values for $m, g$, and $k$ substituted in with the values found earlier. For the "velocity" column, equation 16 is entered as a function with $v_{\text {prev }}$ being the velocity at the previous time and $v_{\text {prev }}^{\prime}$ being the acceleration at the previous time. For the derivative of position column, the velocity at that time is put in. As for the position column, equation 15 is used as a function with $y_{\text {prev }}$ being the position value at the previous time and $y_{\text {prev }}^{\prime}$ being the velocity value at the previous time. $\Delta t$ is .1 seconds in all calculations. Using this process, the rocket's flight path can be determined and graphed.

\section{DISCUSSION}

After all the excel functions are calculated, it was found that the maximum altitude would be shown to be 1294.95 meters at 16.2 seconds into flight (Graph 1). The maximum velocity was shown to be 175.20 meters per second reached 3.1 seconds into flight using this method (Graph 3). The data from the altimeters showed that the rocket actually went 1804.746 meters and was 
reached at 19.75 seconds into flight (Graph 2). The actual maximum velocity was 244.0722 meters per second and was reached 3.85 seconds into flight (Graph 4). The percent error for both the maximum altitude and maximum velocity was about 28 percent.

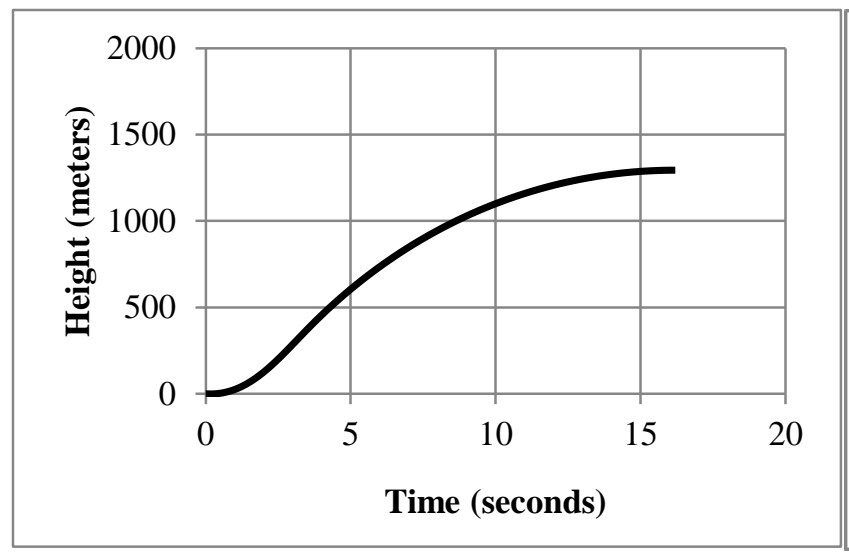

Graph 1: Predicted altitudes

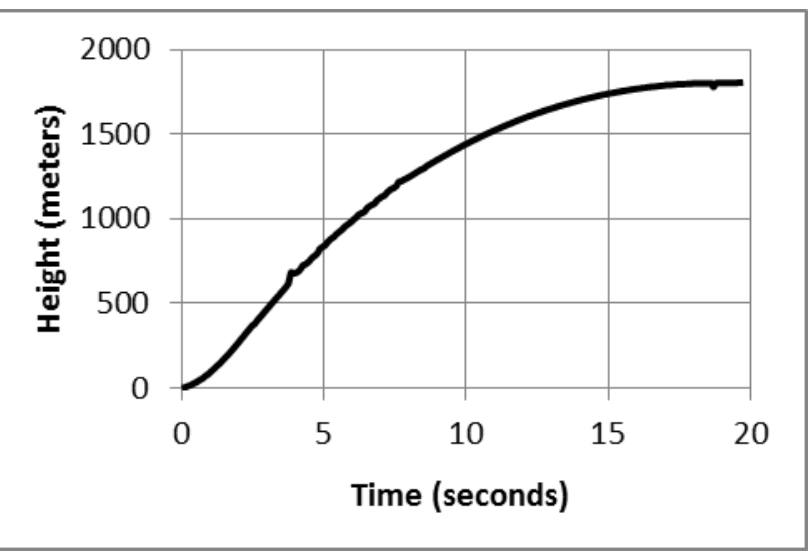

Graph 2: Actual altitudes

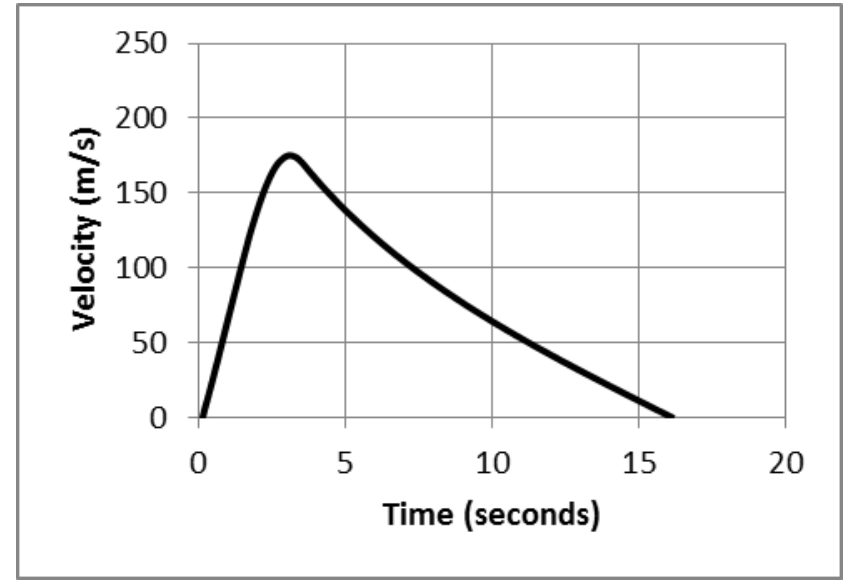

Graph 3: Predicted velocities

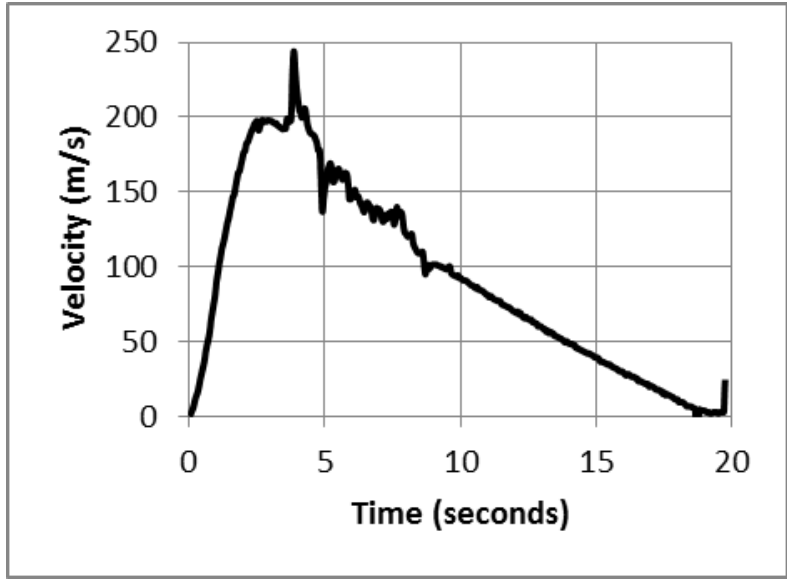

Graph 4: Actual velocities

Recalling that the objective was to get a rough estimate of maximum altitude and velocity to get an idea of the flight path, these results did just that. Since Euler's method is an estimate, it gives some reason for the error in the data. The assumptions made about a stable median mass would affect both the maximum altitude and velocity. The coefficient of drag that was estimated 
at .75 from NASA would give the biggest reason for error since the rocket's true coefficient of drag differs from this one. If the coefficient of drag is changed to .14 , the predicted and actual values equal within a percent error of 1 . However, a coefficient of drag of .14 is not reasonable since it is not streamline. It would be making up for other error in the experiment. The project, though, was able to get a good estimate for the flight path since the graph for the predicted and actual altitudes and velocities look similar. This method of achieving fairly accurate velocities and altitudes can be used in the field of rocketry and in the field of physics with an object having thrust.

\section{CONCLUSION AND RECOMMENDATIONS}

The project utilized Newton's Second Law of Motion, Euler's method, basic physics, and basic calculus to model the flight path of a rocket. The altitude and velocity can be estimated at any point in flight. The predicted values were close to the actual values for altitude and velocity within reason. The recommendations I would make for improving this project would be to first find the correct coefficient of drag by using a wind tunnel. Another recommendation I would make would be to better estimate the mass of the engine as it depletes. I would suggest researching a correlation between the thrust given by the motor and the mass that is used. Also, the calculations could be done using an analytical method using a piece-wise method over the thrust curve. In the end, I would say that this is a plausible way of estimating altitudes and velocities. Pictures from the launch are shown in Figures 5 and 6. 


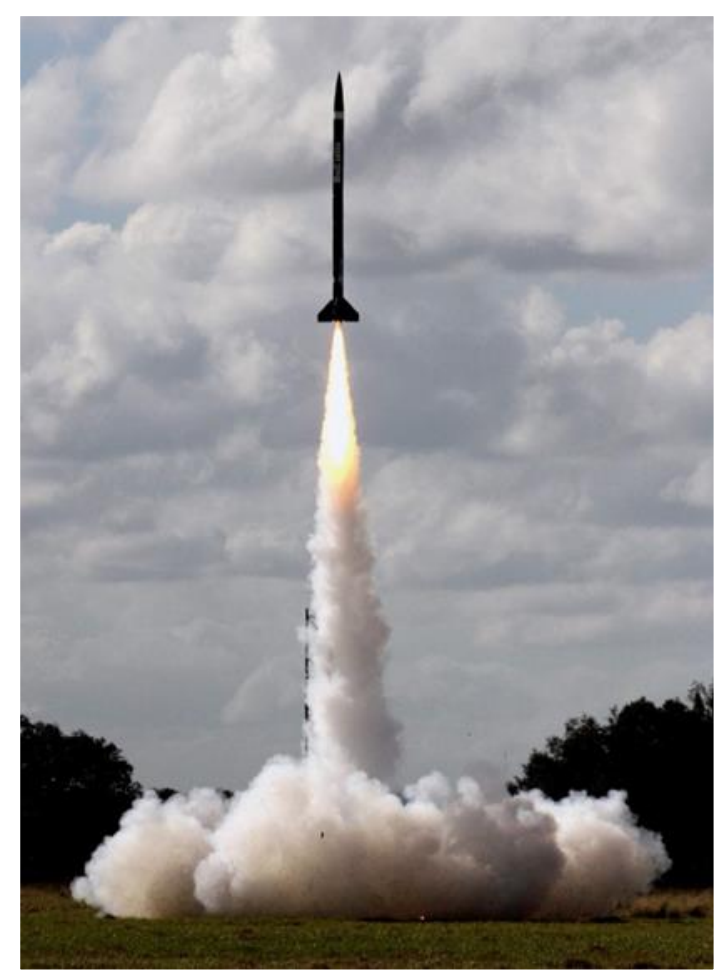

Figure 5: Lift-off of Bullistic-1

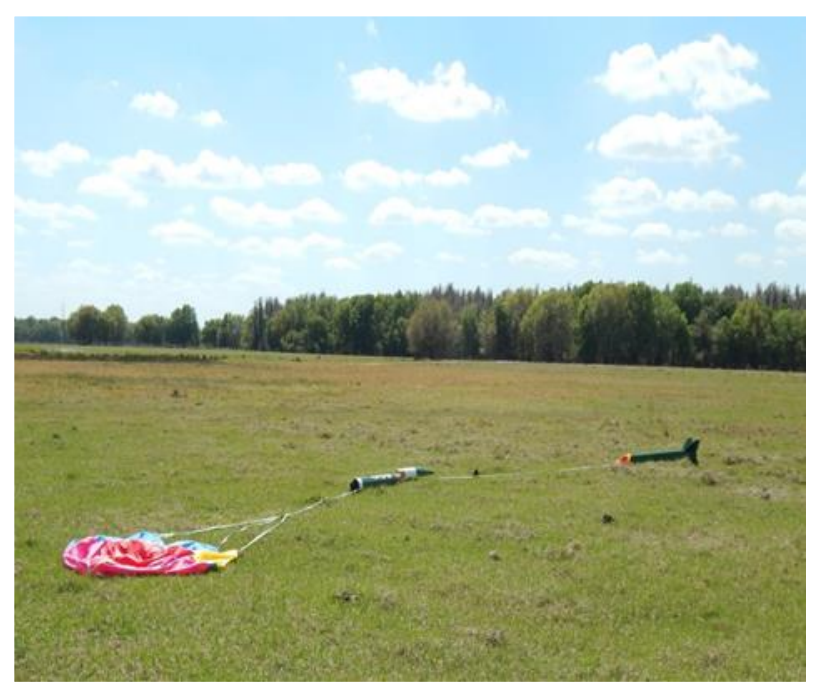

Figure 6: Recovery of Bullistic-1 


\section{NOMENCLATURE}

\begin{tabular}{|c|c|c|c|}
\hline Symbol & Meaning & Units & Value \\
\hline $\mathrm{F}_{\mathrm{G}}$ & Force of gravity & Newton $(\mathrm{N})$ & 245.49 \\
\hline $\mathrm{F}_{\mathrm{D}}$ & Force of drag & Newton $(\mathrm{N})$ & Varies \\
\hline $\mathrm{F}_{\mathrm{y}}$ & Force in y-direction & Newton $(\mathrm{N})$ & Varies \\
\hline $\mathrm{v}$ & Velocity & meters per second $(\mathrm{m} / \mathrm{s})$ & Varies \\
\hline $\mathrm{T}$ & Time & seconds (s) & Varies \\
\hline $\mathrm{M}$ & Mass & kilograms (kg) & 25.025 \\
\hline $\mathrm{m}_{\mathrm{f}}$ & Final mass & kilograms (kg) & 23.55 \\
\hline $\mathrm{m}_{\mathrm{i}}$ & Initial mass & kilograms (kg) & 26.5 \\
\hline $\mathrm{g}$ & Gravity & meters per second squared $\left(\mathrm{m} / \mathrm{s}^{2}\right)$ & 9.81 \\
\hline $\mathrm{T}$ & Thrust & Newton $(\mathrm{N})$ & Varies \\
\hline $\mathrm{a}_{\mathrm{y}}$ & Acceleration in the $y$-direction & meters per second squared $\left(\mathrm{m} / \mathrm{s}^{2}\right)$ & Varies \\
\hline A & Area & meters (m2) & 0.0270479 \\
\hline $\mathrm{C}_{\mathrm{D}}$ & Coefficient of drag & $\mathrm{n} / \mathrm{a}$ & 0.75 \\
\hline$\rho_{\text {air }}$ & Density of air & kilograms per meter cubed $\left(\mathrm{kg} / \mathrm{m}^{3}\right)$ & 1.1337 \\
\hline $\mathrm{T}_{\mathrm{K}}$ & Temperature in Kelvin & Kelvin $(\mathrm{K})$ & 307.35 \\
\hline $\mathrm{k}$ & Coefficient used in drag equation & $\mathrm{kg} / \mathrm{m}$ & 11499 \\
\hline $\mathrm{v}(\mathrm{t})$ & Velocity as a function of time & meters per second $(\mathrm{m} / \mathrm{s})$ & Varies \\
\hline $\mathrm{v}_{\text {prev }}$ & Velocity at the previous point & meters per second $(\mathrm{m} / \mathrm{s})$ & Varies \\
\hline$\Delta \mathrm{t}$ & Change in time & Seconds (s) & 0.1 \\
\hline $\mathrm{V}_{\text {prev }}^{\prime}$ & The acceleration at the previous point & meters per second squared $\left(\mathrm{m} / \mathrm{s}^{2}\right)$ & Varies \\
\hline$y(t)$ & Position as a function of time & meters (s) & Varies \\
\hline yprev & Position at the previous point & meters (s) & Varies \\
\hline$y^{\prime}$ prev & Velocity at the previous point & meters per second $(\mathrm{m} / \mathrm{s})$ & Varies \\
\hline$f(t)$ & Function of time & $\mathrm{n} / \mathrm{a}$ & Varies \\
\hline$f^{\prime}(t)$ & The derivative of the function of time & $\mathrm{n} / \mathrm{a}$ & Varies \\
\hline$f(t+\Delta t)$ & Function of time at the next time point & $\mathrm{n} / \mathrm{a}$ & Varies \\
\hline
\end{tabular}




\section{REFERENCES}

Benson, Tom. Flight of a Model Rocket. n.d. National Aeronautics and Space Administration. 5 November 2014 <http://www.real-world-physics-problems.com/rocket-physics.html>.

Rocket Physics. n.d. 5 Nov 2014 <http://www.real-world-physics-problems.com/rocket-physics.html>.

Shape Effects on Drag. Ed. Tom Benson. n.d. National Aeronautics and Space Administration. 5

November 2014 <http://exploration.grc.nasa.gov/education/rocket/shaped.html>.

Stewart, James. Essential Calculus: Early Transcendentals. 2nd. Belmont: Cengage Learning, 2013.

Young, Hugh D., Roger A. Freedman, A. Lewis Ford, and Francis Weston Sears. Sears and Zemansky's University Physics: With Modern Physics. 13th. Boston: Addison-Wesley, 2012. 